\title{
Quality systems to improve care in older patients with urinary incontinence receiving home care: do they work?
}

\author{
M F M T Du Moulin, ${ }^{1}$ M N Chenault, ${ }^{2}$ F E S Tan, ${ }^{2}$ J P H Hamers, ${ }^{1}$ R H G Halfens ${ }^{1}$
}

${ }^{1}$ Department of Health Care and Nursing Science, Faculty of Health, Medicine and Life Sciences, Maastricht University, Maastricht, The Netherlands ${ }^{2}$ Department of Statistics and Methodology, Faculty of Health, Medicine and Life Sciences, Maastricht University, Maastricht, The Netherlands

\section{Correspondence to}

Monique F M T Du Moulin, Department of Health Care and Nursing Science, Faculty of Health, Medicine and Life

Sciences, Maastricht University, P0 Box 616, Maastricht 6200

$\mathrm{MD}$, The Netherlands; m.dumoulin@zw.unimaas.nl

Accepted 3 October 2009 Published Online First 8 April 2010

\section{ABSTRACT}

Objective To gain insight into the use of quality systems to improve urinary incontinence (UI) care in older adults receiving home care and to assess the associations between these quality systems and UI-related process and patient outcomes.

Design Cross-sectional survey.

Setting 19 home care agencies in the Netherlands comprising 155 home care teams.

Sample 3480 adults aged 65 years and older, screened for UI.

Main outcome measures Percentage of patients with $\mathrm{UI}$, percentage of patients with a diagnosis regarding type of Ul, mean amount of urine loss and mean frequency of urine loss.

Results The quality systems most commonly used included appointing a continence nurse (at the home care agency level) and documenting Ul-related actions in the patient's record (home care teams). Mixed model analyses revealed no associations between the quality systems and the UI process or patient outcomes.

Conclusion Most home care agencies and home care teams claim that they adopt quality systems to improve Ul care for older adults. However, no associations were found between these quality systems and the UI process or patient outcomes. More research with a precise monitoring of implemented systems is therefore needed to gain insight into the effectiveness of quality systems and their applicability in the home care setting.

Urinary incontinence (UI) is a common, debilitating problem mainly affecting older persons. ${ }^{1-4}$ It can have adverse effects on physical health and psychological and social well-being, ${ }^{5-8}$ and increases the risk of institutionalisation. ${ }^{9}$ As advancing age is a risk factor, ${ }^{10}{ }^{11}$ the ageing of the population is expected to drastically increase the number of adults with UI. As older adults prefer to live in their own homes for as long as possible, the demand for home care is also likely to increase. Studies show that about half of the patients receiving home care have UI. ${ }^{11}{ }^{12}$ Addressing the problem adequately will therefore be a challenge for home care agencies.

Despite the available treatment options, research shows that the management of UI often is inconsistent with what is considered optimal care for the condition. ${ }^{13-16}$ Written policies on continence care and training on UI management are sparse, and behavioural treatments are rarely prescribed. ${ }^{17-21}$ Rodriguez and colleagues ${ }^{22}$ report a knowledge-practice gap among qualified care staff who would benefit from training to increase their knowledge and alertness to clients' needs regarding UI care. In the Netherlands, too, it appears that UI management in daily general practice and nursing homes ${ }^{23-26}$ as well as for patients receiving home care ${ }^{27}$ is not always adequate.

To improve UI care, several quality systems can be implemented. A quality system can be described as "all the management activities explicitly designed to monitor, assess and improve the quality of care". ${ }^{28}$ These systems can impact the care process or patient outcomes; several have been described that are used specifically to improve the quality of UI care. ${ }^{29}$ For example, Ouslander and colleagues ${ }^{30}$ identified steps to use as a base for a quality initiative on incontinence; these included a focused history, the identification and treatment of potentially reversible causes and chart documentation. Other quality systems concern UI education and the appointment of a healthcare worker dedicated to UI care. ${ }^{31}$ Proper assessment of UI and documentation of the patient's continence status also help provide good care. $^{32} 33$

Wagner et $a l^{28}$ reviewed the effectiveness of quality systems in nursing homes and found some evidence that training and guidelines significantly reduce the prevalence of UI. However, little is known about the use and the effects of quality systems to improve UI care for older adults receiving care from home care agencies. Indeed, it is unclear which quality system(s) home care agencies tend to adopt, and whether they are effective. To measure effectiveness, process and outcome measures can be analysed. ${ }^{28}$ Process measures have to do with the process of care (eg, making a diagnosis as to type of UI like stress or urge incontinence), while outcome measures relate to UI outcomes (eg, prevalence and frequency). These quality indicators are expected to positively influence the process of UI care and UI outcomes.

The aim of this study is to gain insight into the use of quality systems by home care agencies to improve UI care in the Netherlands. Our second aim is to evaluate the relationship between these quality systems on UI outcomes (the prevalence and frequency of UI and amount of urine loss) and processes (whether a diagnosis as to UI type is made). The following questions are addressed:

1. What quality systems do home care agencies use to improve UI care, and how many such agencies, and the teams within the agencies, actually use these systems? 
2. What is the relationship between these quality systems and UI prevalence and the number of patients diagnosed as having a particular UI type?

3. What is the relationship between these quality systems and UI severity in terms of the amount and frequency of urine loss?

\section{METHOD \\ Design}

This study is part of the Annual National Prevalence Measurement of Care Problems of Maastricht University. The design is a cross-sectional survey conducted during routine examination of patients by home care nurses. The data were collected in April 2006

\section{Dutch National Prevalence Measurement of Healthcare Problems}

Each year, all Dutch healthcare organisations are invited to participate in the National Prevalence Measurement of Healthcare Problems. ${ }^{34}$ Participating organisations include hospitals, nursing homes, homes for older persons, institutions for the physically and mentally handicapped, and home care agencies. Each organisation appoints a coordinator responsible for organising and implementing the study. Data collection is conducted by nurses trained to use the standardised forms; patients are included after providing informed consent. They have the right to refuse to participate and to withdraw from the study at any time without consequence.

The present study used the data pertaining to UI collected from 19 home care agencies (14\% of the total number of home care agencies in the Netherlands).

\section{Population and setting}

Adults aged 65 years or older who were living at home and receiving care from a home care agency were eligible to participate. Only people who have applied to an independent assessment agency (CIZ) for home care approval can receive home care from a home care agency. The assessment agency assesses the person's needs to determine the type and amount of care required. After the CIZ has granted the approval, the person can contact a home care agency.

\section{Data collection}

Each home care agency is composed of home care teams responsible for a geographically defined subset of patients. Therefore, data collection took place at three levels: the home care agency, the home care team and the patient.

Quality systems used at the level of the home care agency differ from those of the home care teams. Also, even if a home care agency has no quality systems, individual teams can still adopt one or more quality systems. At the home care agency level, the available quality systems are as follows: "continence nurse", a nurse who is educated and specialised in the care for incontinent patients; "UI protocol", a protocol with treatment options for UI that is agreed upon in writing by the home care agency; "updating of protocol", there is a person or a committee specialised in UI care who adjusts the UI protocol whenever new developments or insights in UI care have occurred; this person also brings it to the attention of the healthcare workers; "UI education", a training or meeting about the treatment of UI within the past 2 years was scored (yes/no) using a list set up by a multidisciplinary team of experts. Likewise, at the home care team level, availability was scored (yes/no) using a list ("presence of a nurse with special UI focus", a person within the team who is dedicated to UI (eg, advising patients on incontinence pads) but who is less educated when compared with a continence nurse; "documentation in patient record", it is registered which actions regarding the treatment of UI should take place for patients with UI; "check as to whether UI protocol is used", it is checked, verbal or in writing, whether the protocol on UI is actually used by the healthcare workers; "UI brochure", a brochure on the causes and the treatments of UI that is given to patients and their family).

At the patient level, a standardised questionnaire was used by the home care nurses that were part of the home care agencies participating in the measurement. These nurses are responsible for the care of the patients and know these patients well. We expect that the nurse's familiarity with the patient will increase the reliability of the collected data. The nurse used the collected information from the patient and the patient's record to answer the questions. The informal care giver (in most cases a close relative) was approached for those patients unable to provide answers. Data on the following patient characteristics were collected: age, sex, body mass index (BMI) and mobility ("bedridden", "confined to chair", "walks now and then" or "walks regularly").

To identify whether patients had UI, nurses asked about the frequency of involuntary urine loss $(1=$ never, $2=$ three or four times a month, $3=$ a few times a week, $4=$ every day). Patients rated as "never" were regarded as continent. The nurse also rated the amount of urine loss ( $1=$ drops, $2=$ small splashes, $3=$ entire bladder contents). The nurse also registered whether a diagnosis had been made regarding type of UI (yes/no).

\section{Analysis}

Analyses were performed using SPSS V.15. The relationship between patient characteristics and continence status was analysed using the $\chi^{2}$ test for categorical variables and the t test for continuous variables. As the data have a multilevel structure in which home care teams are embedded within agencies, random intercept models were defined to estimate outcome values relative to quality systems. As the research questions address the effectiveness of interventions that are determined at the team level, the data was aggregated at this level. The outcome variables then became mean percentage of patients with UI, mean percentage of patients who had been diagnosed as having a particular UI type, mean amount of urine loss and mean frequency of urine loss. Patient characteristics such as age, sex, mobility and BMI were also aggregated at the team level and considered covariates.

It appeared that when a quality system was indeed present, it was often combined with one or more other quality systems. Therefore, all observed combinations of quality systems were classed as separate groups for comparison purposes. Comparisons were made between teams with (combinations of) quality system(s) and teams without quality systems, as well as between individual quality systems. To simplify the analysis, the combinations of systems at the home care agency level were considered separately from those at the team level. Additionally, combinations of systems were compared pairwise, applying the multiple-comparison least significant difference method with CIs for the difference, with the reference category being presented. Furthermore, the relationship between the outcome variables and the number of quality systems at the home care agency team level, which can range from 0 to 4 , was also investigated. It was checked to ensure that the normality assumptions were met regarding the random effects and residuals. 
Table 1 Urinary incontinence (UI) status and patient characteristics at individual and team levels

\begin{tabular}{|c|c|c|c|c|c|}
\hline $\begin{array}{l}\text { Patient } \\
\text { characteristics }\end{array}$ & Incontinent, n (\%) & Continent, n (\%) & $\begin{array}{l}95 \% \mathrm{Cl} \text { for } \\
\text { difference }\end{array}$ & $\begin{array}{l}\text { Mean (SD) team } \\
\text { level }\end{array}$ & $\begin{array}{l}95 \% \mathrm{Cl} \text { mean } \\
\% \text { team level } \\
\end{array}$ \\
\hline \multicolumn{6}{|l|}{ Sex } \\
\hline Male & $421(26.7)^{*}$ & $785(41.4)$ & & 34.4 & \\
\hline Female & $1154(73.3)$ & $1109(58.6)$ & & 65.6 & 63.4 to 67.8 \\
\hline Age (mean, SD) & $82.1(7.1)$ & $80.1(7.0)$ & 0.8 to $1.7 \dagger$ & $81.5(2.3)$ & 81.2 to 81.9 \\
\hline BMI (mean, SD) & $26.8(5.6)$ & $25.5(4.8)$ & 0.9 to $1.6 \dagger$ & $25.1(1.6)$ & 25.8 to 26.4 \\
\hline \multicolumn{6}{|l|}{ Mobility } \\
\hline Bedridden & $61(1.8)^{*}$ & $32(4.0)$ & 1.1 to 3.4 & $3.7(6.4)$ & 2.7 to 4.7 \\
\hline Confined to chair & $153(4.4)$ & $79(10.1)$ & 4.0 to 7.5 & $7.3(9.3)$ & 5.8 to 8.7 \\
\hline Walks now and then & $533(27.1)$ & $493(35.1)$ & 4.9 to 11.1 & $32.0(17.1)$ & 29.3 to 34.7 \\
\hline Walks regularly & $770(66.7)$ & $1212(50.8)$ & 12.7 to 19.3 & $59.1(18.3)$ & 54.1 to 59.9 \\
\hline
\end{tabular}

To assess the reliability of the measurements, a random sample of 20 patients were assessed independently by another nurse.

\section{RESULTS}

In 2006, a total of 19 home care agencies participated in the Dutch National Prevalence Measurement of Healthcare Problems. These agencies consisted of 155 home care teams caring for 3480 patients aged 65 years or older who were screened for UI. Table 1 presents the mean age and BMI according to status regarding continence. Furthermore, the distribution of sex and mobility are presented according to continence status. Incontinence appears to be related to being a woman $\left(\chi^{2}=82.1, \mathrm{df}=1\right.$, $\mathrm{p}<0.0005)$ and mobility $\left(\chi^{2}=106.8, \mathrm{df}=3, \mathrm{p}<0.0005\right)$. In the last column, patient characteristics at the team level are presented. When considering the total sample, $45.3 \%$ of the patients were incontinent. Aggregated at the team level, the percentage incontinence was $47.3 \%$ (SD 16.0).
The number of teams per home care agency varies from 1 to 21 , and the number of patients per team varies from 2 to 117 . Of the 19 home care agencies, a total of 10 (53\%) used one or more quality systems: $3(16 \%)$ used a UI protocol, 7 (37\%) used a continence nurse, 4 (21\%) used UI education and $4(21 \%)$ updated their protocols.

Of the 155 teams, 79 (51\%) appointed a nurse with a special UI focus, 29 (18.7\%) checked whether the UI protocol was used, $121(78.1 \%)$ documented UI-related actions in the patient's record and 10 (6.5\%) used brochures on UI.

Agreement between the nurses' ratings was good with $\kappa$ statistics varying between 0.69 and 0.94 .

\section{UI prevalence}

To identify the quality systems associated with UI prevalence, all quality systems (separate and/or combined) were entered into random intercept models: one for the quality systems at the home care agency level and one for the systems at the team

Table 2 Mean percentage of incontinence by availability of quality system

\begin{tabular}{|c|c|c|c|c|c|c|}
\hline Quality systems & $\begin{array}{l}\text { No of teams } \\
\text { with quality } \\
\text { system(s) }\end{array}$ & $\begin{array}{l}\text { Raw percentages } \\
\% \text { (SD) }\end{array}$ & $\begin{array}{l}\text { Adjusted } \\
\text { estimated mean } \\
\% \text { of UI }\end{array}$ & $\begin{array}{l}\text { Mean } \\
\text { difference }\end{array}$ & $\begin{array}{l}95 \% \mathrm{Cl} \\
\text { interval of } \\
\text { difference }\end{array}$ & p Value* \\
\hline \multicolumn{7}{|l|}{ Agency level† } \\
\hline$A$ & 9 & $37.8(5.6)$ & 38.9 & 9.6 & -6.7 to 25.9 & 0.21 \\
\hline$A B$ & 18 & $50.6(11.8)$ & 51.3 & -2.8 & -19.5 to 13.9 & 0.66 \\
\hline ACD & 7 & $63.9(22)$ & 58.5 & -10.0 & -27.0 to 7.0 & 0.22 \\
\hline $\mathrm{BCD}$ & 29 & $40.4(13.8)$ & 40.4 & 8.2 & -4.1 to 20.4 & 0.15 \\
\hline C & 17 & $42.6(10.6)$ & 42.5 & 6.0 & -5.3 to 17.3 & 0.26 \\
\hline$D$ & 2 & $67.0(3.2)$ & 68.7 & -20.2 & -43.1 to 2.8 & 0.08 \\
\hline $\mathrm{BC}$ & 1 & 55.2 & 56.9 & -8.4 & -38.9 to 22.1 & 0.59 \\
\hline None (reference) & 72 & $49.2(17.2)$ & 48.5 & & & \\
\hline \multicolumn{7}{|l|}{ Team levelł } \\
\hline a & 6 & $51.4(16.0)$ & 51.6 & -2.7 & 17.1 to 11.6 & 0.71 \\
\hline$a b$ & 4 & $50.9(19.7)$ & 53.9 & -5.0 & -22.4 to 12.4 & 0.57 \\
\hline ac & 48 & $46.9(12.9)$ & 47.7 & 1.2 & -7.7 to 10.0 & 0.80 \\
\hline$a b c$ & 11 & $47.4(16.3)$ & 48.6 & 0.3 & -11.7 to 12.2 & 0.96 \\
\hline acd & 1 & 26.9 & 33.0 & 15.9 & -15.1 to 46.9 & 0.31 \\
\hline$b$ & 1 & 28.6 & 32.8 & 16.1 & -14.7 to 46.9 & 0.30 \\
\hline bc & 4 & $40.5(9.9)$ & 42.1 & 6.7 & -9.8 to 23.3 & 0.42 \\
\hline c & 48 & $45.6(16.4)$ & 43.9 & 4.9 & -4.2 to 14.0 & 0.28 \\
\hline abcd & 9 & $58.1(22.3)$ & 51.9 & -3.0 & -17.8 to 11.8 & 0.68 \\
\hline None (reference) & 23 & $48.5(18.4)$ & 48.9 & & & \\
\hline
\end{tabular}

UI, Urinary incontinence; A, Protocol on incontinence; B, Updating of protocol; C, Continence nurse; D, UI education; a, nurse with special UI focus; $b$, check as to whether $\mathrm{UI}$ protocol is used; $c$, documentation in patient record; $d$, UI brochure.

*When compared with teams (within home care agencies) without quality systems.

†Adjusted for mobility (\% bedridden): $b=0.47, p=0.021$.

$\ddagger$ Adjusted for mobility (\% bedridden): $b=0.62, p=0.004$ and mean BMI: $b=1.63, p=0.043$. 
level. Table 2 shows the adjusted estimated mean prevalence of UI. No relationship between the mean percentage of UI in teams using quality systems (separate or combined) was observed when compared with teams without quality systems.

There was a significant difference between combinations of quality systems at the home care agency level $(\mathrm{F}=3.121$, $\mathrm{df}=7,155, \mathrm{p}=0.004$ ). Pairwise comparisons (not shown in table) of (combinations of) the quality systems showed that teams from home care agencies providing UI education (D), had a higher percentage of UI compared with teams from home care agencies with a UI protocol (A) $(\mathrm{p}=0.029,95 \% \mathrm{CI}$ for difference: 3.36 to 56.19$)$; a continence nurse (C) ( $p=0.035,95 \%$ CI 1.95 to 50.48 ); or a combination of a continence nurse, education and protocol updating (BCD) ( $p=0.023,95 \%$ CI 4.22 to 52.48). Pairwise comparisons of the teams' quality system combinations revealed no statistically significant differences. Also, there appeared to be no relation between percentage incontinence and the number of implemented quality systems at either the home care agency or the team level.

\section{Diagnosis regarding type of $\mathrm{UI}$}

The data showed that 16 teams never made diagnoses of UI type, whereas 17 teams always did. Of the 17 teams who always made a diagnosis, there were 9 teams who had no quality systems at the home care agency level and 3 with no quality systems at the team level. $\chi^{2}$ Tests did not indicate a relationship between whether a diagnosis was always or never made and the individual quality systems. Random intercept model analysis was performed for the 122 teams who sometimes made a diagnosis to measure associations between quality systems and mean percentage of diagnoses of UI type. No associations were found (see table 3).

Pairwise comparison (not shown in table) of (combinations of) the quality systems revealed no differences in the outcome measure. In other words, no (combinations of) quality systems performed better than any other on the outcome measure (per cent of diagnoses). Moreover, there appeared to be no relation- ship between the outcome variable and the number of quality systems implemented at either the home care agency or the team level.

\section{Frequency and amount of urine loss}

To identify which quality systems were associated with mean frequency of UI loss, all quality systems (separate and combined) were entered into random intercept models: one for the quality systems at the agency level and one for those at the team level. This was also done for mean amount of urine loss. The overall $\mathrm{F}$ tests were not statistically significant for either outcome whether considering the quality systems at the agency or team level. Tables 4 and 5 present the adjusted estimated means and CIs.

\section{Frequency of UI loss}

In spite of the fact that the overall $\mathrm{F}$ tests were not statistically significant, we made pairwise comparisons (data not shown) of (combinations of) the quality systems. At the home care agency level, no differences in mean frequency of UI could be discerned. Pairwise comparisons of the (combinations of) quality systems at the team level showed that, although not quite statistically significant, teams using all four quality systems (abcd) seemed to have better outcomes (lower mean frequency of UI) than a team only using a nurse with a UI focus (a) $(p=0.076,95 \% \mathrm{CI}$ -0.43 to 0.02 ); those using two, namely a nurse with a UI focus and documentation in patient record $(\mathrm{ac})(\mathrm{p}=0.056,95 \% \mathrm{CI}$ : -0.45 to 0.01 ); or those using three quality systems, namely a nurse with a UI focus, documentation in patient record and check as to whether UI protocol was used (abc) ( $p=0.075,95 \%$ $\mathrm{CI}$ : -0.52 to 0.03 ). However, taking multiple testing into account, there were no significant differences between the quality systems at the team level $(\mathrm{F}=0.929, \mathrm{df}=9,155, \mathrm{p}=0.502)$. The number of implemented quality systems at either the home care agency or the team level did not seem to be related to the frequency of urine loss.

Table 3 Mean percentage of patients with urinary incontinence (UI) diagnoses by availability of quality systems

\begin{tabular}{lllllll}
\hline $\begin{array}{l}\text { Quality } \\
\text { systems }\end{array}$ & $\begin{array}{l}\text { No of teams with } \\
\text { quality system(s) }\end{array}$ & $\begin{array}{l}\text { Raw } \\
\text { percentages } \\
\text { \% (SD) }\end{array}$ & $\begin{array}{l}\text { Adjusted estimated } \\
\text { mean \% of diagnoses }\end{array}$ & $\begin{array}{l}\text { Mean } \\
\text { difference }\end{array}$ & $\begin{array}{l}\mathbf{9 5 \%} \text { CI } \\
\text { interval of } \\
\text { difference }\end{array}$ & p Value* \\
\hline Agency level & & & & & & \\
$\quad$ A & 8 & $39.3(17.6)$ & 39.3 & 8.4 & -16.7 to 33.5 & 0.47 \\
AB & 14 & $50.3(23.1)$ & 50.4 & -2.7 & -27.2 to 21.8 & 0.79 \\
ACD & 6 & $53.1(21.0)$ & 53.1 & -5.4 & -31.4 to 20.7 & 0.66 \\
B & 16 & $38.3(21.2)$ & 39.3 & 8.4 & -9.2 to 25.9 & 0.32 \\
BCD & 22 & $40.8(21.9)$ & 41.4 & 6.3 & -12.2 to 24.9 & 0.45 \\
BC & 1 & 51.5 & 51.5 & -3.8 & -51.0 to 43.3 & 0.87 \\
$\quad$ None (reference) & 55 & $46.6(24.6)$ & 47.7 & & & \\
Team level & & & & -10.3 & -33.7 to 13.1 & 0.39 \\
a & 5 & $52.1(22.5)$ & 54.7 & -4.1 & -18.0 to 9.8 & 0.56 \\
ac & 40 & $47.9(22.5)$ & 48.5 & -7.8 & -27.0 to 11.4 & 0.43 \\
abc & 9 & $51.1(23.9)$ & 52.2 & -13.7 & -60.4 to 32.9 & 0.56 \\
acd & 1 & 57.1 & 58.1 & -8.1 & -31.3 to 15.0 & 0.48 \\
abcd & 7 & $51.8(19.4)$ & 52.6 & -16.4 & -62.9 to 30.0 & 0.49 \\
b & 1 & 58.3 & 60.9 & -2.9 & -31.1 to 25.3 & 0.84 \\
bc & 3 & $46.6(3.0)$ & 47.3 & 7.7 & -6.6 to 21.9 & 0.29 \\
C & 39 & $37.1(22.5)$ & 36.8 & & & \\
None (reference) & 17 & $45.0(26.3)$ & 44.4 & & & \\
\hline
\end{tabular}

A, protocol on incontinence; $B$, updating of protocol; $C$, continence nurse; $D$, UI education; $a$, nurse with special UI focus; $b$, check as to whether $\mathrm{UI}$ protocol is used; c, documentation in patient record, $\mathrm{d}$, UI brochure.

*When compared with teams (within home care agencies) without quality systems. 
Table 4 Mean frequency of urinary incontinence (UI) loss by availability of quality systems

\begin{tabular}{|c|c|c|c|c|c|c|}
\hline $\begin{array}{l}\text { Quality } \\
\text { systems }\end{array}$ & $\begin{array}{l}\text { No of teams } \\
\text { with quality system(s) }\end{array}$ & $\begin{array}{l}\text { Unadjusted } \\
\text { mean frequency }\end{array}$ & $\begin{array}{l}\text { Adjusted estimated } \\
\text { mean frequency } \ddagger\end{array}$ & $\begin{array}{l}\text { Mean } \\
\text { difference }\end{array}$ & $\begin{array}{l}95 \% \mathrm{Cl} \\
\text { interval } \\
\text { difference }\end{array}$ & p Value* \\
\hline \multicolumn{7}{|l|}{ Agency level $†$} \\
\hline$A$ & 9 & $3.55(0.23)$ & 3.57 & -0.01 & -0.3 to 0.2 & 0.91 \\
\hline$A B$ & 18 & $3.50(0.31)$ & 3.51 & 0.05 & -0.2 to 0.3 & 0.63 \\
\hline ACD & 7 & $3.46(0.49)$ & 3.37 & 0.19 & -0.1 to 0.5 & 0.17 \\
\hline $\mathrm{BC}$ & 1 & 3.31 & 3.34 & 0.21 & -0.4 to 0.8 & 0.49 \\
\hline BCD & 29 & $3.59(0.31)$ & 3.59 & -0.03 & -0.2 to 0.1 & 0.70 \\
\hline C & 17 & $3.51(0.26)$ & 3.51 & 0.05 & -0.1 to 0.2 & 0.60 \\
\hline $\mathrm{D}$ & 2 & $3.28(0.16)$ & 3.31 & 0.2 & -0.2 to 0.7 & 0.26 \\
\hline None (reference) & 72 & $3.56(0.30)$ & 3.56 & & & \\
\hline \multicolumn{7}{|l|}{ Team level } \\
\hline a & 6 & $3.64(0.23)$ & 3.62 & -0.12 & -0.4 to 0.2 & 0.38 \\
\hline$a b$ & 4 & $3.53(0.35)$ & 3.56 & -0.06 & -0.4 to 0.3 & 0.71 \\
\hline ac & 48 & $3.55(0.28)$ & 3.56 & -0.06 & -0.2 to 0.1 & 0.42 \\
\hline$a b c$ & 11 & $3.60(0.32)$ & 3.59 & -0.09 & -0.3 to 0.1 & 0.43 \\
\hline acd & 1 & 3.86 & 3.89 & -0.38 & -1.0 to 0.2 & 0.22 \\
\hline abcd & 9 & $3.41(0.44)$ & 3.34 & 0.16 & -0.1 to 0.4 & 0.20 \\
\hline $\mathrm{b}$ & 1 & 3.17 & 3.19 & 0.31 & -0.3 to 0.9 & 0.32 \\
\hline bc & 4 & $3.57(0.12)$ & 3.60 & -0.10 & -0.4 to 0.2 & 0.56 \\
\hline c & 48 & $3.54(0.28)$ & 3.54 & -0.04 & -0.2 to 0.1 & 0.58 \\
\hline None (reference) & 23 & $3.50(0.37)$ & 3.50 & & & \\
\hline
\end{tabular}

\section{Amount of UI loss}

Pairwise comparisons (data not shown) of (combinations of) quality systems at the home care agency level revealed a trend showing a lower mean amount of UI loss in teams from home care agencies with a UI protocol and updating of the protocol, compared with teams in agencies using UI education $(\mathrm{p}=0.071$, $95 \% \mathrm{CI}:-0.65$ to 001 ) or in agencies with a combination of UI protocol, a continence nurse and education $(p=0.056,95 \% \mathrm{CI}$ : -0.96 to 0.04$)$. However, the overall $F$ test at 1.42 was not significant $(\mathrm{df}=4,7 ; \mathrm{p}=0.502)$. Pairwise comparison of (combinations) of quality systems at the team level revealed no differences. The number of implemented quality systems at either the home care agency or the team level did not seem to be related to the amount of urine loss.

\section{DISCUSSION}

This study showed that $53 \%$ of the home care agencies and $86 \%$ of the home care teams used one or more quality systems to improve care for patients with UI. Documentation in patient's records (78\% of the teams) and use of a continence nurse $(37 \%$ of the home care agencies) were the most common systems. However, results showed no associations between the quality systems as measured in our study and UI outcomes.

Some methodological issues should be mentioned when interpreting the results. This study had a cross-sectional design and cannot be used to make claims about cause-effect relationships between the outcome measures and quality systems used. It also provides no insight into the effects on UI outcomes of quality systems used in the past or implemented at an earlier date. Furthermore, it was not possible to check whether the home care agencies and teams that indicated using quality systems in fact did so; research in other settings shows occasional discrepancies between documentation about care-process delivery in the patient's record and care that is actually provided. ${ }^{35}$ However, to check the availability of the quality systems used by the home care agencies and teams is beyond the scope of this prevalence measurement. To what extent this played a role in our study cannot be known. Also, whether there are quality systems other than those measured by the prevalence measurement are being used to improve UI is also unknown. As is stated in the Method section, the data was aggregated at the team level as this was the lowest level at which there was variation in healthcare systems. Clearly, aggregating the data involves the loss of information-that is, the outcome at the patient level is not being studied. The outcome variable then became percentage of incontinence at the team level, and therefore this resulted in wider CIs than would have been obtained if the analysis had occurred at the patient level. Nevertheless, this aggregated approach seems the most appropriate for addressing the research questions.

We were surprised to find no associations between the quality systems and the process and outcome measures. After all, studies in other settings have reported several quality systems as having a positive effect on UI. For instance, one study with a pretestpost-test design conducted in seven nursing homes revealed that staff training significantly reduced incontinence prevalence from $43 \%$ to $21 \% .{ }^{36}$ On the basis of a quasi-experiment, Collette et al ${ }^{19}$ also reported that an educational programme for nursing staff significantly improved nurses' knowledge, skills and attitudes. Randomised controlled trials have also showed that continence nurses have a positive effect among community-dwelling women. $^{37-39}$ Finally, using a prospective evaluation study, Sampselle et al ${ }^{40}$ found that using an evidence-based protocol benefited women's continence status.

Our study occurred in the home of the patient rather than in an institutional setting, in contrast to most of the studies mentioned above. It may be that the sometimes, small numbers of teams adopting certain combinations of quality systems may have resulted in too little power for our random intercept 
Table 5 Mean amount of urine loss by availability of quality systems

\begin{tabular}{|c|c|c|c|c|c|c|}
\hline $\begin{array}{l}\text { Quality } \\
\text { systems }\end{array}$ & $\begin{array}{l}\text { No of teams with } \\
\text { quality system(s) }\end{array}$ & $\begin{array}{l}\text { Unadjusted mean } \\
\text { urine loss }\end{array}$ & $\begin{array}{l}\text { Adjusted } \\
\text { estimated } \\
\text { mean urine loss } \S\end{array}$ & $\begin{array}{l}\text { Mean } \\
\text { difference }\end{array}$ & $\begin{array}{l}95 \% \mathrm{Cl} \\
\text { interval } \\
\text { difference }\end{array}$ & p Value* \\
\hline \multicolumn{7}{|l|}{ Agency level† } \\
\hline$A$ & 9 & $1.93(0.36)$ & 1.96 & -0.55 & -0.3 to 0.20 & 0.66 \\
\hline$A B$ & 18 & $1.71(0.31)$ & 1.70 & 0.20 & -0.03 to 0.43 & 0.08 \\
\hline ACD & 7 & $2.1(0.58)$ & 2.02 & -0.12 & -0.4 to 0.2 & 0.39 \\
\hline $\mathrm{BC}$ & 1 & 1.86 & 1.92 & -0.02 & -0.7 to 0.6 & 0.95 \\
\hline BCD & 29 & $1.90(0.31)$ & 1.91 & -0.01 & -0.2 to 0.2 & 0.92 \\
\hline C & 17 & $1.83(0.27)$ & 1.82 & 0.08 & -0.1 to 0.3 & 0.41 \\
\hline $\mathrm{D}$ & 2 & $2.17(0.32)$ & 2.16 & -0.26 & -0.7 to 0.2 & 0.28 \\
\hline None (reference) & 72 & $1.90(0.35)$ & 1.90 & & & \\
\hline \multicolumn{7}{|l|}{ Team levelł } \\
\hline$a$ & 6 & $1.84(0.28)$ & 1.86 & 0.10 & -0.2 to 0.4 & 0.51 \\
\hline$a b$ & 4 & $1.97(0.31)$ & 2.05 & -0.08 & -0.4 to 0.3 & 0.67 \\
\hline ac & 48 & $1.83(0.29)$ & 1.81 & 0.15 & -0.03 to 0.3 & 0.10 \\
\hline$a b c$ & 11 & $1.95(0.39)$ & 1.97 & -0.001 & -0.3 to 0.3 & 0.99 \\
\hline acd & 1 & 2.00 & 1.98 & -0.01 & -0.7 to 0.7 & 0.97 \\
\hline abcd & 9 & $1.96(0.53)$ & 1.92 & 0.04 & -0.2 to 0.3 & 0.77 \\
\hline$b$ & 1 & 1.67 & 1.67 & 0.3 & -0.4 to 1.0 & 0.40 \\
\hline bc & 4 & $1.87(0.23)$ & 1.87 & 0.1 & -0.3 to 0.5 & 0.60 \\
\hline c & 48 & $1.87(0.35)$ & 1.90 & 0.07 & -0.1 to 0.3 & 0.47 \\
\hline None (reference) & 23 & $1.95(0.38)$ & 1.97 & & & \\
\hline
\end{tabular}

analysis to find significant associations. Moreover, in contrast to patients in hospitals or nursing homes, patients receiving home care are not under the constant surveillance of, for example, a nurse, thus potentially reducing the consistency of the implementation of systems. There is also a possibility that home care agencies or teams using one or more quality systems may be the very ones with relatively large proportions of patients with UI.

Nevertheless, this was the first study carried out to measure whether the availability of quality systems in home care agencies and home care teams can be associated with better UI care. It can be questioned whether agencies with quality systems will tend to attract clients with UI relatively more. Often, however, it is the client who chooses the home care agency. Therefore, it can be assumed that this does not result in response bias.

Many patients receiving home care services are old, and most have multiple medical conditions and disabilities. Therefore, quality systems to improve UI care in the home healthcare setting must address aspects specifically related to UI in this group (eg, greater support may be required to ensure compliance and sustain motivation, and the assessment process may take longer as all relevant information may not be obtained at once). ${ }^{41}$ However, whether these aspects are included in the quality systems is not known, as our study only investigated whether a certain system (eg, a protocol) was available in the home care agency or team. No data were gathered on the content of protocols, for example, or the way in which the systems were adopted by the home healthcare workers.

The fact that we found no associations between the quality systems and UI outcomes may also result from certain staff or patient characteristics. Research has shown that healthcare workers may have negative attitudes about the effectiveness of treatment for UI. ${ }^{42}$ Time constraints, too, may force them to focus care on more urgent problems, ${ }^{43}$ and patients, who tend to view UI as part of the ageing process, may be reluctant to ask for help or follow treatment. ${ }^{44-46}$ Thus, despite the availability of quality systems to improve UI care, healthcare workers may not use them because of their own or the patient's lack of motivation.

Another factor that may have influenced our findings is that we do not know how the quality systems are implemented in home healthcare. The implementation of new working methods may be hampered by several factors (eg, insufficient knowledge of the healthcare worker's experience, values, attitude, needs and priorities, as well as economic and administrative factors). ${ }^{47}$ Therefore, the extent to which the quality systems are accepted and carried out by home healthcare workers remains unknown.

\section{CONCLUSION}

Home care agencies are confronted with caring for a growing number of older people with UI who also have physical and/or mental impairments. There are several quality systems that home healthcare workers can adopt to improve UI care; however, our study revealed a limited use of such systems. In our study, we did not check whether quality systems that were flagged by the home care agencies and teams were actually present. Also, other quality systems or systems that have been used in the past were not measured. In this study, we found no associations between quality systems and UI outcomes. Factors like inadequate implementation of quality systems or lack of motivation to address UI on the part of either the home healthcare worker or the patient may have influenced our results. Therefore, more insight is needed into the content of quality systems to improve UI care and their applicability in the home care setting.

\section{Competing interests None.}

Ethics approval This study was conducted with the approval of the University Hospital Maastricht Medical Ethical Committee. 
Contributors MFMTDM was involved in study conception, design, data collection, analysis and drafting of the manuscript. JPHH and RHGH were involved in study conception, design, data collection, analysis and critical revisions for important intellectual content, and supervised the study. MNC and FEST provided statistical expertise and critical revisions of the paper.

Provenance and peer review Not commissioned; externally peer reviewed.

\section{REFERENCES}

1. Rohr G, Stovring $\mathrm{H}$, Christensen $\mathrm{K}$, et al. Characteristics of middle-aged and elderly women with urinary incontinence. Scand J Prim Health Care 2005;23:203-8

2. Espino DV, Palmer RF, Miles TP, et al. Prevalence and severity of urinary incontinence in elderly Mexican-American women. J Am Geriatr Soc 2003;51:1580-6.

3. Danforth K, Townsend M, Lifford K, et al. Risk factors for urinary incontinence among middle-aged women. Am J Obstet Gynecol 2006:194:339-45.

4. Melville JL, Katon W, Delany K, et al. Urinary incontinence in US women-a population-based study. Arch Intern Med 2005;165:537-42.

5. Ko Y, Lin S, Salmon J, et al. The impact of urinary incontinence on quality of life of the elderly. Am J Manag Care 2005;11:103-11.

6. Engberg S, Sereika SM, Weber E, et al. Prevalence and recognition of depressive symptoms among homebound older adults with urinary incontinence. J Geriatr Psychiatry Neurol 2001;14:130-9.

7. van der Vaart $\mathbf{C H}$, de Leeuw JR, Roovers JP, et al. De invloed van urineincontinentie op de kwaliteit van leven bij thuiswonende Nederlandse vrouwen van 45-70 jaar. Ned Tijdschr Geneeskd 2000;144:894-7.

8. Fultz NH, Burgio K, Diokno AC, et al. Burden of stress urinary incontinence for community-dwelling women. Am J Obstet Gynecol 2003;189:1275-82.

9. Thom DH, Haan MN, Van den Eeden SK. Medically recognized urinary incontinence and risks of hospitalization, nursing home admission and mortality. Age Ageing 1997;26:367-74

10. Hannestad YS, Rortveit G, Sandvik H, et al. the Norwegian EPINCONT study. Epidemiology of Incontinence in the County of N-T. A community-based epidemiological survey of female urinary incontinence: the Norwegian EPINCONT study. Epidemiology of Incontinence in the County of Nord-Trondelag. J Clin Epidemiol 2000;53:1150-7.

11. Landi F, Cesari M, Russo A, et al. Potentially reversible risk factors and urinary incontinence in frail older people living in community. Age Ageing 2003;32:194-9.

12. Du Moulin MFMT, Hamers JPH, Ambergen AW, et al. Prevalence of urinary incontinence among community-dwelling adults receiving home care. Res Nurs Health 2008;31:604-12; doi: 10.1002/nur.20291.

13. Gibbs CF, Johnson MT, Ouslander JG. Office management of geriatric urinary incontinence. Am J Med 2007;120:211-20.

14. Mardon RE, Halim S, Pawlson LG, et al. Management of urinary incontinence in Medicare Managed Care Beneficiaries. Arch Intern Med 2006;166:1128-33.

15. Penning-van Beest FJA, Sturkenboom MCJM, Bemelmans BLH, et al. Undertreatment of urinary incontinence in general practice. Ann Pharmacother 2005;39:17-21.

16. Engberg S, Kincade J, Thompson D. Future directions for incontinence research with frail elders. Nurs Res 2004:53:22-8.

17. Watson N, Brink CA, Zimmer J, et al. Use of the Agency for Health Care Policy and Research Urinary Incontinence Guideline in nursing homes. J Am Geriatr Soc 2003:51:1779-86.

18. Schnelle J, Cadogan M, Grbic D, et al. A standardized quality assessment system to evaluate incontinence care in the nursing home. J Am Geriatr Soc 2003:51:1754-61.

19. Collette C, Leclerc G, Tu le M. Effectiveness of a geriatric urinary incontinence educational program for nursing staff. Can J Nurs Leadersh 2003:16:99-109.

20. Mayor S. Incontinence management is inadequate, UK audit shows. Br Med J 2005;331:1226.

21. Gnanadesigan $\mathbf{N}$, Saliba D, Roth $\mathrm{CP}$, et al. The quality of care provided to vulnerable older community-based patients with urinary incontinence. J Am Med Dir Assoc 2004;5:141-6

22. Rodriguez NA, Sackley CM, Badger FJ. Exploring the facets of continence care: a continence survey of care homes for older people in Birmingham. J Clin Nurs 2005;16:954-62.
23. Inspectie voor de Gezondheidszorg. Verpleeghuiszorg: kwaliteitsslag is gaande. Resultaat van geïntensiveerd tozicht 2005-2006. (In Dutch). Den Haag: Inspectie voo de Gezondheidszorg, 2006.

24. Teunissen D, Bosch van den W, Weel C, et al. Urinary incontinence in the elderly: attitudes and experiences of general practitioners; a focus group study. Scand J Prim Health Care 2006:24:56-61.

25. Albers - Heitner $\mathbf{P}$, Berghmans LCM, Nieman F, et al. How do patients with urinary incontinence perceive care given by their general practitioner? A cross-sectional study. Int J Clin Pract 2008;62:508-15.

26. Albers-Heitner P, Berghmans LCM, Nieman F, et al. Adherence to professional guidelines for patients with urinary incontinence by general practitioners: a crosssectional study. J Eval Clin Pract 2008;14:807-11.

27. Du Moulin MFMT, Hamers JPH, Ambergen AW, et al. Urinary incontinence in olde adults receiving home care; diagnosis and strategies. Scand J Caring Sci 2008;doi: 10.1111/j.1471-6712.2008.00610.x.

28. Wagner C, Wal van der G, Groenewegen $P$, et al. The effectiveness of quality systems in nursing homes: a review. Qual Saf Health Care. 2001; 10:211-17.

29. Institute of Medicine IOM. http://www.iom.edu/cms/8089.aspx 2008.

30. Ouslander JG. Quality improvement initiatives for urinary incontinence in nursing homes. J Am Med Dir Assoc 2007;8:6-11.

31. Mueller C, Cain H. Comprehensive management of urinary incontinence through quality improvement efforts. Geriatr Nurs 2002;23:82-7.

32. Awad L. Verantwoorde zorg bij toiletgang en incontinentie. Zeist: SCA hygiene products Nederland B.V.; 2006.

33. Lagro Janssen TL, Breedveldt Boer HP, Dongen JJAM, et al. NHG-Standaard Incontinentie voor urine. Huisarts Wet 2006;49:501-10.

34. Halfens $\mathbf{R}$, Janssen $\mathrm{M}$, Meijers J, et al. Rapportage resultaten Landelijke Prevalentiemeting Zorgproblemen 2005. Maastricht: Universiteit Maastricht, 2005.

35. Schnelle J, Bates-Jensen B, Chu L, et al. Accuracy of nursing home medical record information about care-process delivery: implications for staff management and improvement. J Am Geriatr Soc 2004;52:1378-83.

36. Schnelle J, Newman D, White $\mathbf{M}$, et al. Maintaining continence in nursing home residents through the application of industrial quality control. Gerontologist 1993;33:114-21

37. Borrie MJ, Bawden M, Speechley M, et al. Interventions led by nurse continence advisers in the management of urinary incontinence: a randomized controlled trial. Can Med Assoc J 2002;166:1267-73.

38. Williams K , Assassa P, Cooper N, et al. Clinical and cost-effectiveness of a new nurse-led continence service: a randomised controlled trial. Br J Gen Pract 2005:55:696-703.

39. Du Moulin MFMT, Hamers JPH, Paulus A, et al. Effects of introducing a specialized nurse in the care of community-dwelling women suffering from urinary incontinence. J Wound Ostomy Continence Nurs 2007;34:631-40.

40. Sampselle CM, Wyman J, Thomas C, et al. Continence for women: a test of AWHONN's evidence-based protocol in clinical practice. J Wound Ostomy Continence Nurs 2000;27:109-17.

41. Getliffe K, Dolman M, eds. Promoting continence; a clinical and research resource. 2nd edn. London: Baillière Tindall, 2003

42. Resnick B, Keilman L, Calabrese B, et al. Nursing staff beliefs and expectations about continence care in nursing homes. J Wound Ostomy Continence Nurs 2006;33:610-18

43. Cheater FM, Baker R, Gillies $\mathrm{C}$, et al. The nature and impact of urinary incontinence experienced by patients receiving community nursing services: a cross-sectional cohort study. Int J Nurs Stud 2006; doi: 10.1016/j.jinurstu.2006.09.006.

44. Hägglund D, Wadensten B. Fear of humiliation inhibits women's care-seeking behaviour for long-term urinary incontinence. Scand J Caring Sci 2007; 21:305-12.

45. Teunissen D, Weel C, Lagro Janssen TL. Urinary incontinence in older people living in the community: examining help-seeking behaviour. $\mathrm{Br} J$ Gen Pract 2005:55:776-82.

46. Dugan E, Roberts CP, Cohen SJ, et al. Why older community-dwelling adults do not discuss urinary incontinence with their primary care physicians. J Am Geriatr Soc 2001;49:462-5.

47. Grol R, Wensing M. Implementatie; effectieve verandering in de patiëntenzorg. 2nd edn. Maarssen: Elsevier gezondheidszorg, 2001. 